\title{
Variables influencing the likelihood of cardiac dysrhythmias during extracorporeal shock wave lithotripsy
}

\author{
Thomas A. A. Skinner, MSc; Richard W. Norman, MD, FRCSC
}

Department of Urology, Dalhousie University, Halifax, NS

Cite as: Can Urol Assoc J 2012;6(2):107-10. Epub July 5, 2011. http://dx.doi.org/10.5489/ cuaj. 10122

\section{Abstract}

Introduction: Extracorporeal shock wave lithotripsy (ESWL) is a safe and effective treatment of upper urinary tract calculi. While serious side effects are rare, transient cardiac dysrhythmias (CD) may be associated with ESWL. The exact etiology of these events, which are often unpredictable, is poorly understood. Awareness of CD during ESWL and identification of risk factors for developing them could help clinicians predict and manage them safely and effectively. The current study examines selected variables to determine whether they may predispose individuals to developing CD during ESWL.

Methods: We compared 16 patients who experienced CD during ESWL to 56 control patients. Cases and controls were compared with respect to several continuous and discrete variables, including age, pre-treatment heart rate, number of shocks received during treatment, energy setting of the lithotripter, gender, presence of a ureteric stent, previous ESWL and side being treated.

Results: Cardiac dysrhythmias occurred more frequently in younger patients and in those being treated for right-sided stones. The other variables did not influence the likelihood of CD. All CD resolved promptly following conversion to electrocardiogram (ECG)-gating. Conclusion: Younger age and right-sided treatment predisposed individuals to developing CD during ESWL. Careful ECG monitoring should be performed during treatment.

\section{Résumé}

Introduction : La lithotripsie extra-corporelle par ondes de choc (LECOC) est un traitement sûr et efficace pour les calculs des voies urinaires supérieures. Les effets secondaires graves sont rares, mais des dysrythmies cardiaques (DC) transitoires peuvent être associées à la LECOC. L'étiologie précise de ces manifestations souvent imprévisibles est mal établie. La reconnaissance d'une DC pendant la LECOC et des facteurs de risque de cette manifestation pourrait aider les cliniciens à en prédire la survenue et à traiter cette manifestation avec efficacité et en toute sécurité. L'étude présentée ici examine des variables sélectionnées pour déterminer si ces dernières peuvent prédisposer à la survenue d'une DC pendant une LECOC.

Méthodologie : Nous avons comparé 16 patients ayant présenté une DC pendant une LECOC et 56 patients témoins. Les cas de DC et les témoins ont été comparés sur le plan de plusieurs variables continues et ponctuelles, dont l'âge, la fréquence cardiaque avant le traitement, le nombre d'ondes de choc reçues pendant le traitement, le niveau d'énergie établi pour le lithotriteur, le sexe, la présence $d^{\prime}$ une endoprothèse urétérale, le recours antérieur à une LECOC et le côté traité.

Résultats : Les dysrythmies cardiaques ont été plus fréquentes chez les patients plus jeunes et les personnes traitées pour des calculs du côté droit. Les autres variables n'ont eu aucun effet sur la probabilité de survenue de DC. Toutes les DC se sont résorbées rapidement après conversion par synchronisation à l'électrocardiographie (ECG). Conclusion : Un âge moins avancé et un traitement du côté droit prédisposent les patients à une DC pendant un traitement par LECOC. II faut assurer une surveillance attentive par ECG pendant le traitement.

\section{Introduction}

Extracorporeal shock wave lithotripsy (ESWL) was developed to treat human urolithiasis three decades ago. ${ }^{1}$ It has been established as a safe and effective therapy for upper urinary tract calculi and has become the primary method of intervention for many urologists. ${ }^{2-6}$ While serious side effects are rare, transient cardiac dysrhythmias (CD) may be associated with ESWL. ${ }^{7-12}$ Such events have been documented at rates of $60 \%$ to $80 \%$ with early lithotripters and have led to the development of electrocardiogram (ECG)-gated shock wave delivery systems for management and prevention. ${ }^{11,13,14}$

Although modern lithotripters have a lower incidence of CD during treatment, they still occur in up to $21 \%$ of patients depending on the device used. ${ }^{13-15}$ Due to the increased treatment time required for ECG-gated lithotripsy, most procedures are performed at a fixed-rate putting patients at a higher risk of developing CD. ${ }^{13,14}$ Most CD identified are benign, unifocal premature ventricular contractions (PVC), 
but severe multifocal PVC and supraventricular tachycardias can also occur. ${ }^{4,14,16}$ Almost all CD return to normal sinus rhythm following conversion to ECG-gated shock delivery and pose no intraoperative or postoperative consequences; consequently, the importance of preventing such events remains unknown. ${ }^{15}$

The exact mechanism of abnormal cardiac activity during ESWL is poorly understood and consistent evidence on predisposing risk factors has not been established. Although most $C D$ have no cardiac sequelae, improved awareness and predictability of CD could optimize its prevention and management, as well as the efficiency and safety of the ESWL treatment (e.g., being prepared to intervene promptly with ECG-gating when treating those at highest risk of CD throughout their lithotripsy). ${ }^{13,15}$

There is limited published information regarding patient risk factors; most of the existing literature is dated and involved older generation lithotripters. In this study, we sought to identify patient variables associated with the development of CD during ESWL with a modern electromagnetic device.

\section{Methods}

Out of 342 patients undergoing ESWL at 120 shocks per minute, we identified 16 cases $(4.7 \%)$ of significant $C D$ during treatment in a prospective manner. All cases demonstrated frequent runs of bigeminy, trigeminy and/or multiple episodes of uni-/multi-focal PVC and were determined by the attending anesthesiologist to require conversion to ECGgated shock delivery for patient safety. Although the events were considered worrisome, all CD resolved promptly following conversion to ECG-gating. No other interventions were necessary and no acute side effects were noted.

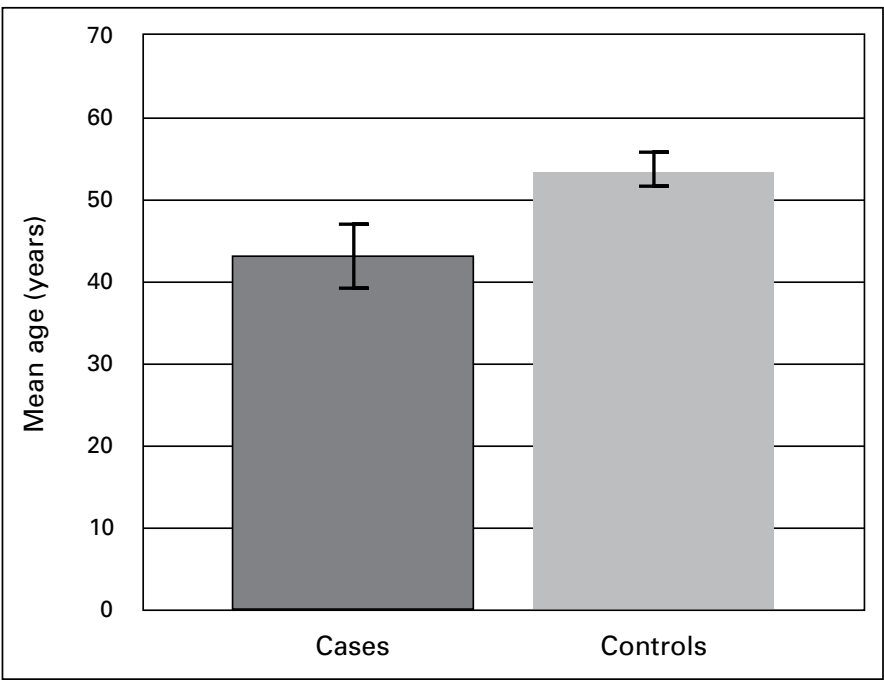

Fig. 1. Effect of age on cardiac dysrhythmias during extracorporeal shock wave lithotripsy $(p<0.01)$.
Medical charts from the 16 patients who developed CD were compared with those of 56 control patients who did not experience $\mathrm{CD}$ during $\mathrm{ESWL}$; these comparisons were done on the same day and by the same treating urologist and anesthesiologist. Individuals with a previously known cardiac dysrhythmia or artificial pacemaker were excluded.

Cases and controls were compared with respect to continuous variables, including age, pre-treatment heart rate, number of shocks received during treatment and energy setting of the lithotripter. Both groups were also compared with respect to discrete variables as gender, presence of a ureteric stent, previous ESWL and side of treatment.

All patients were treated for renal stones. The ESWL was administered with a Siemens LITHOSKOP lithotripter (Siemens AG Healthcare, Erlangen, Germany). The LITHOSKOP unit is a dry lithotripter that uses an electromagnetic shock wave system. Cardiac electrical activity was observed using continuous intraoperative electrocardiography.

Data were analyzed by multivariate analysis. Logistic regression was performed to determine if each variable was associated with the occurrence of $C D$ events. A $p$ value of $\leq 0.05$ was considered significant.

\section{Results}

Patients who experienced CD during ESWL were significantly younger (mean age 43 years, range 21-73; standard error of measurement $[S E M] 4)$ than those who did not develop CD (mean age 54 years, range 18-86; SEM 2) $(p<0.01)$ (Fig 1). There was no statistical difference in the pre-treatment heart

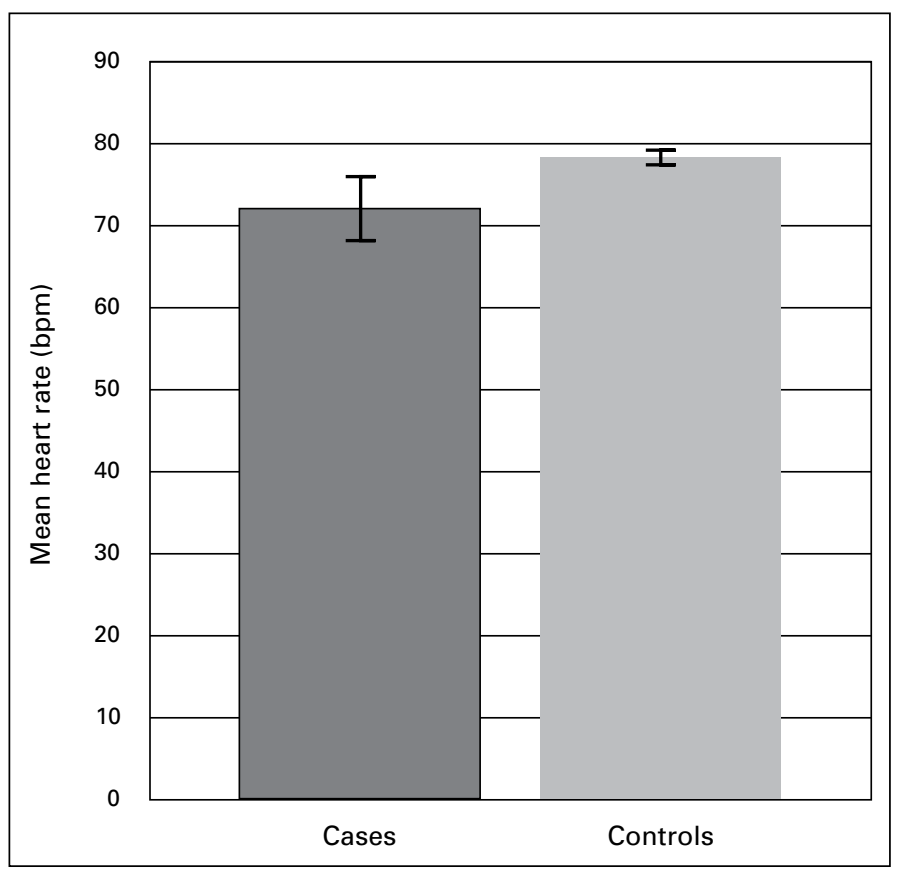

Fig. 2. Effect of pre-treatment heart rate on cardiac dysrhythmias during extracorporeal shock wave lithotripsy (mean \pm SEM [not significant]). 


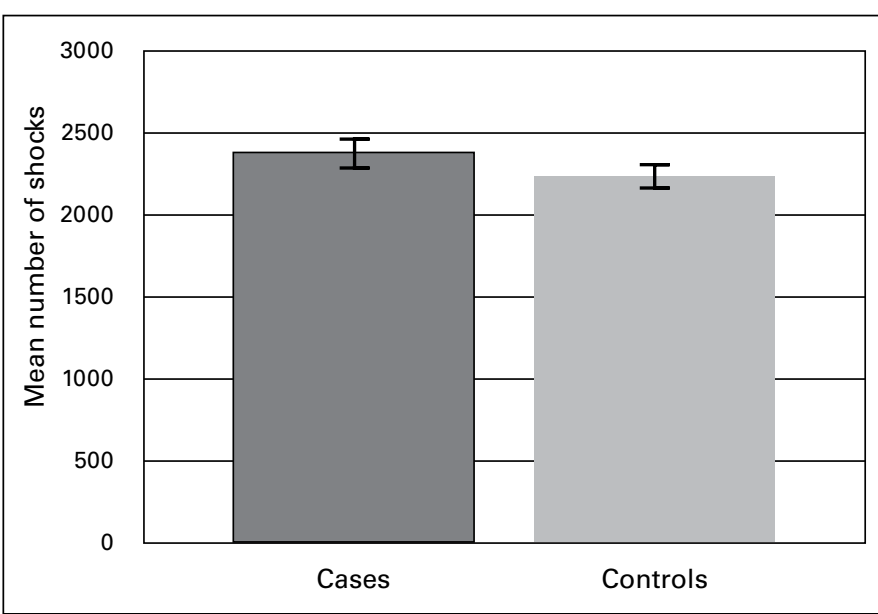

Fig. 3. Effect of number of shocks on dysrhythmias during extracorporeal shock wave lithotripsy (mean \pm SEM [not significant]).

rate (Fig. 2). As this figure illustrates, the mean heart rate in the Cases group was $73 \mathrm{bpm}$ (range 55-100; SEM 4); in the Controls group, the mean heart rate was $79 \mathrm{bpm}$ (range 49-110; SEM 2). We also tallied the number of shocks delivered during treatment (Fig. 3). In the Cases, the mean shock number was 2327 (range 1500-3000; SEM 143) and in the Controls, the mean shock number was 2245 (range 10003500; SEM 92). The mean energy setting of the lithotripter used during ESWL in the Cases was 3.5 (range 3-6; SEM 0.2) and in the Controls 3.6 (range 3-8; SEM 0.1) (Fig. 4).

Of the 16 cases of $C D, 13$ were treated for right-sided stone(s) $(81 \%), 1$ patient was treated for a left-sided stone $(6 \%)$ and 2 patients were treated for bilateral stones (13\%). In contrast, of the 56 control patients, 23 were treated for right-sided stone(s) $(41 \%), 28$ were treated for left-sided stone(s) $(50 \%)$, and 5 were treated for bilateral stones (9\%). The odds ratio analysis revealed that treatment of right-sided stone(s) is a risk factor for the development of CD during ESWL ( $p=0.005)$ (Fig. 5).

Analysis of the other discrete variables showed no significance to previous ESWL, presence of a ureteric stent or gender (Fig. 5).

\section{Discussion}

Extracorporeal shock wave lithotripsy has profoundly enhanced the treatment of upper urinary tract stones and allowed urolithiasis to be treated in a non-invasive outpatient setting. Improvements in modern devices have enabled the use of modifiable fixed-rate shock wave delivery providing better fragmentation and greater efficiency. Despite these benefits, the use of ungated lithotripsy increases the risk of developing CD. ${ }^{17-21}$ The impact of different ungated fixed rates is unknown.

Previous studies have failed to determine the physiologic cause of this unusual cardiac activity during ESWL.

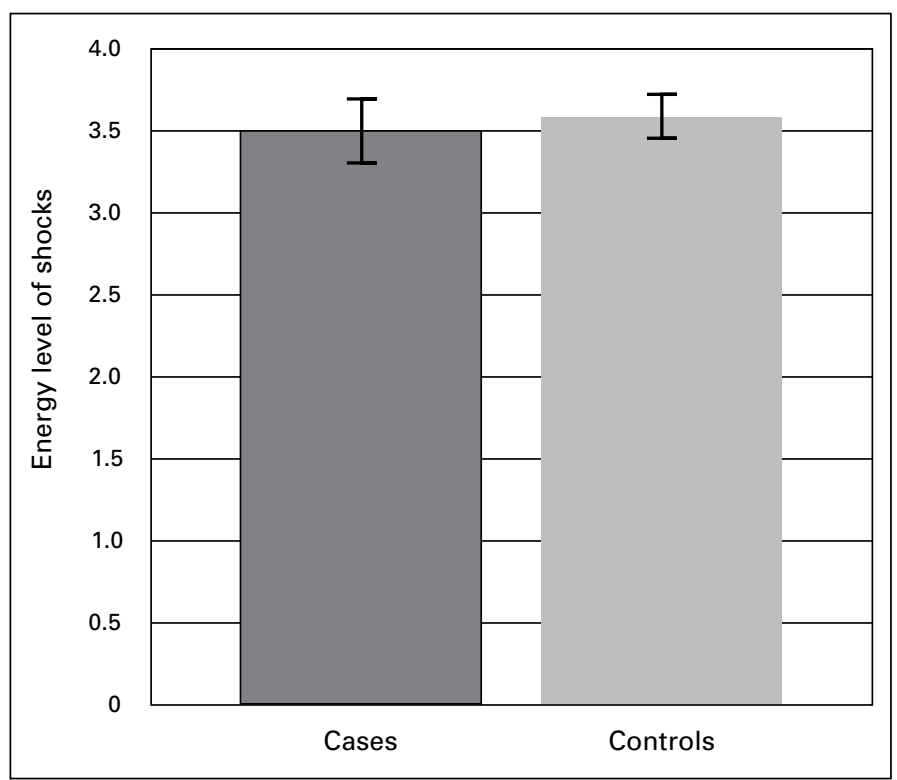

Fig. 4. Effect of energy level on cardiac dysrhythmias during extracorporeal shock wave lithotripsy (mean \pm SEM [not significant]).

Currently, the most prominent theories suggest that CD may be caused by direct mechanical stimulation of the myocardium or a neurohumoral response to treatment or both. These dysrhythmic events also remain unexplained with respect to their predisposing risk factors and long-term impact. Our study provides analysis of patient variables and their influence on the likelihood of CD occurring during ESWL and reports two risk factors that predispose individuals to developing these events when treated with a Siemens LITHOSKOP lithotripter.

We confirm previous findings that individuals treated for right-sided renal stones are more likely to develop CD than those treated for left-sided ones. ${ }^{20,22}$ Other studies have shown that there is a higher rate of dysrhythmias in patients with renal stones compared with ureteric stones. ${ }^{13,14}$ Cardiac dysrhythmias can be induced in an animal model by focusing shockwaves at the apex of the heart. ${ }^{23}$ These findings suggest that the location of the stone is an important predisposing factor in the development of CD and this supports the hypothesis that direct pressure stimulation of the myocardium contributes to CD during ESWL. ${ }^{12}$

This is the first time that younger patients have been shown to have an increased risk of experiencing CD during ESWL. It is known that cardiac neurohumoral regulation changes over time and that norepinephrine synthesis and release decreases with age. ${ }^{24,25}$ There is evidence that the autonomic nervous system has some responsibility in the generation of $\mathrm{CD}$ and it is known that epinephrine is elevated following ESWL. ${ }^{26,27}$ Although we present a statistically significant age difference between the groups, there is insufficient evidence to conclude that 11 years is a clinically significant difference. It would be presumptuous to attribute 


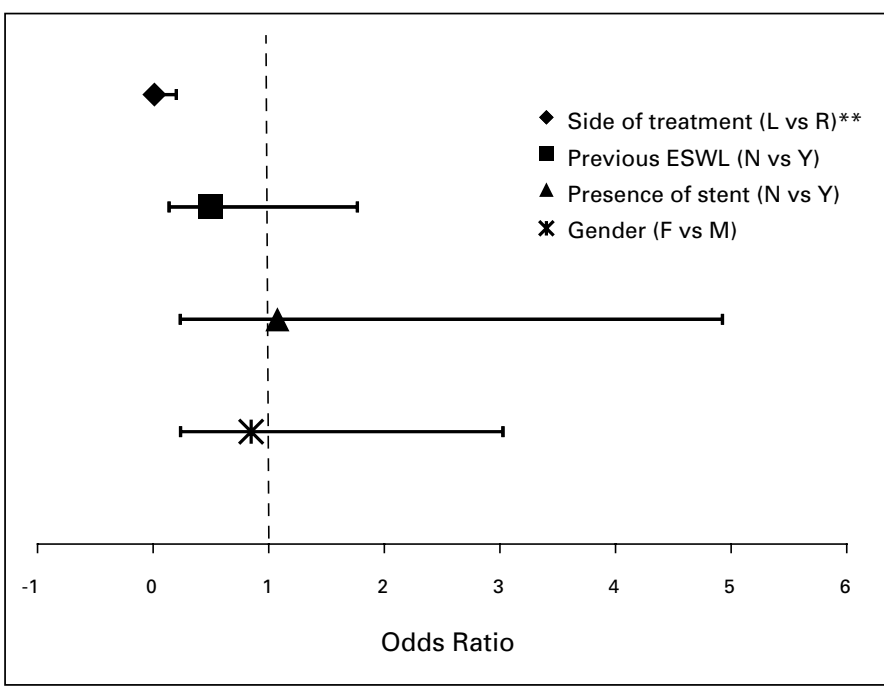

Fig. 5. Forest plot of discrete variables $\left(\mathrm{OR} \pm 95 \% \mathrm{Cl}\left[{ }^{* *} p=0.005\right]\right)$. L: left; R: right; N: no; Y: yes; F: female; M: male.

a change in neurohumoral response to such a small difference in age. These findings do, however, lend credence to the argument that more than mechanical factors are at play.

We found no difference between gender, number of shocks or lithotripter energy setting. Ganem and colleagues demonstrated no link between CD and gender or shock number and Zanetti and colleagues found no association between the number or energy of shock waves. ${ }^{14,18} \mathrm{We}$ also agree with another study showing no effect of prior ESWL treatment or pre-treatment heart rate on the development of CD. ${ }^{20}$ Finally, the presence of a ureteric stent did not influence the likelihood of $C D$, which is consistent with the safety of performing ESWL with a stent in place. ${ }^{11,21}$

\section{Conclusion}

Our study provides evidence supporting multifactorial causes of CD during ESWL. The true consequence of these events remains to be determined; severe, life-threatening $\mathrm{CD}$ during treatment are exceedingly rare. The fact that $\mathrm{CD}$ that occur during ESWL do not progress to significant physiologic events and that they cease promptly with ECG-gating warrants further investigation into understanding these phenomena. The finding that younger individuals and those being treated for right-sided stones are at increased risk of developing CD during ESWL with a Siemens LITHOSKOP device is a start. Careful ECG monitoring should be performed during treatment.

Acknowledgement: The authors acknowledge the assistance of Ellen Forbes in collecting the data.

Competing interests: None declared.
This paper has been peer-reviewed.

\section{References}

1. Chaussy C, Brendel W, Schmiedt E. Extracorporeally induced destruction of kidney stones by shock waves. Lancet 1980;2:1265-8.

2. Tolon M, Miroglu C, Erol H, et al. A report on extracorporeal shock wave lithotripsy results on 1,569 renal units in an outpatient clinic. J Urol 1991;145:695-8.

3. Chaussy C, Schmiedt E, Jocham D, et al. First clinical experience with extracorporeally induced destruction of kidney stones by shock waves. J Urol 1982;127:417-20.

4. Walts LF, Atlee IL 3rd. Supraventricular tachycardia associated with extracorporeal shock wave lithotripsy. Anesthesiology 1986;65:521-3.

5. Drach GW, Dretler S, Fair W, et al. Report of the United States cooperative study of extracorporeal shock wave lithotripsy. J Urol 1986;135:1127-33.

6. Riehle RA Jr, Fair WR, Vaughan ED Jr. Extracorporeal shock-wave lithotripsy for upper urinary tract calculi. One year's experience at a single center. JAMA 1986;255:2043-8.

7. Doran 0 , Foley B. Acute complications following extracorporeal shock-wave lithotripsy for renal and ureteric calculi. Emerg Med Australas 2008;20:105-11.

8. Fugita $\mathrm{OE}$, Trigo-Rocha $\mathrm{F}$, Mitre Al, et al. Splenic rupture and abscess after extracorporeal shock wave lithotripsy. Urology 1998;52:322-3.

9. Gugulakis $A G$, Matsagas $M I$, Liapis $C D$, et al. Rupture of the abdominal aorta following extracorporeal shock-wave lithotripsy. Eur J Surg 1998;164:233-5.

10. White WM, Morris SA, Klein FA, et al. Splenic rupture following shock wave lithotripsy. Can I Urol 2008; 15:4196-9.

11. Skolarikos A, Alivizatos $G$, de la Rosette J. Extracorporeal shock wave lithotripsy 25 years later: complications and their prevention. Eur Urol 2006;50:981-90; discussion 990.

12. Ector $H$, Janssens $L$, Baert $L$, et al. Extracorporeal shock wave lithotripsy and cardiac arrhythmias. Pacing Clin Electrophysiol 1989;12:1910-7.

13. Winters JC, Macaluso JN Jr. Ungated Medstone outpatient lithotripsy. J Urol 1995;153(3 P† 1):593-5.

14. Ganem JP, Carson CC. Cardiac arrhythmias with external fixed-rate signal generators in shock wave lithotripsy with the Medstone lithotripter. Urology 1998;51:548-52.

15. Rhee K, Palmer JS. Ungated extracorporeal shock wave lithotripsy in children: an initial series. Urology 2006;67:392-3

16. Billote DB, Challapalli RM, Nadler RB. Unintended supraventricular tachycardia induced by extracorporeal shock wave lithotripsy. Anesthesiology 1998;88:830-2.

17. Chaussy C, Schuller J, Schmiedt E, et al. Extracorporeal shock-wave lithotripsy (ESWL) for treatment of urolithiasis. Urology 1984;23(5 Spec No):59-66.

18. Zanetti G, Ostini F, Montanari E, et al. Cardiac dysrhythmias induced by extracorporeal shockwave lithotripsy. J Endourol 1999;13:409-12.

19. Kohrmann KU, Rassweiler JJ, Manning M, et al. The clinical introduction of a third generation lithotriptor: Modulith SL 20. J Urol 1995;153:1379-83.

20. Greenstein A, Kaver I, Lechtman V, et al. Cardiac arrhythmias during nonsynchronized extracorporeal shock wave lithotripsy. J Urol 1995; 154:1321-2.

21. Shouman AM, Ghoneim IA, EIShenoufy A, et al. Safety of ungated shockwave lithotripsy in pediatric patients. J Pediatr Urol 2009;5:119-21.

22. Eaton MP, Erturk EN. Serum troponin levels are not increased in patients with ventricular arrhythmias during shock wave lithotripsy. J Urol 2003;170 (6 Pt 1):2195-7.

23. Delius $M$, Hoffmann $E$, Steinbeck $G$, et al. Biological effects of shock waves: induction of arhythmia in piglet hearts. Ultrasound Med Biol 1994;20:279-85.

24. Frolkis VV, Shevtchuk VG, Verkhratsky NS, et al. Mechanisms of neurohumoral regulation of heart function in aging. Exp Aging Res 1979;5:441-77.

25. Snyder DL, Gayheart-Walsten PA, Rhie S, et al. Effect of age, gender, rat strain, and dietary restriction, on norepinephrine release from cardiac synaptosomes. J Gerontol A Biol Sci Med Sci 1998;53:B33-41.

26. Kataoka H. Cardiac dysrhythmias related to extracorporeal shock wave lithotripsy using a piezoelectric lithotriptor in patients with kidney stones. J Urol 1995;153:1390-4.

27. Ishihara $\mathrm{M}$, Ishidori $\mathrm{N}$, Uchida $\mathrm{H}$, et al. Relationship between plasma hormones and ventricular premature contractions in extracorporeal shock wave lithotripsy-significance of human atrial natriuretic peptide (hANP) [in Japanese]. Hinyokika Kivo 1999;45:169-73.

Correspondence: Dr. Richard W. Norman, Suite 620, 5991 Spring Garden Rd, Halifax, NS B3H 1Y6; richard.norman@dal.ca 